\title{
Linseed Oil and its Tendency to Self-Heat
}

\author{
JUITA ${ }^{1}$, BOGDAN Z. DLUGOGORSKI ${ }^{1}$, ERIC M. KENNEDY ${ }^{1}$, and JOHN C. MACKIE ${ }^{1,2}$ \\ ${ }^{1}$ Process Safety and Environmental Protection Group \\ School of Engineering \\ The University of Newcastle, Callaghan, NSW 2308, Australia \\ ${ }^{2}$ School of Chemistry \\ The University of Sydney \\ NSW 2006, Australia
}

\begin{abstract}
Several varieties of linseed oil are commercially available, and they have been used for many applications especially in decorative furniture finishing and as an oil painting medium. The addition of metallic driers to the linseed oil is a common practice, as it improves the drying rate of the paint. Several cases of fires have been reported, often involving rags soaked with linseed oil which have not been disposed of properly, and it is generally agreed that metal salts in the linseed oil play an important role in the spontaneous ignition of the oil. This paper investigates several types of linseed oil sold in the market and their tendency to cause self-heating of cotton which has been impregnated with linseed oil obtained from various sources.
\end{abstract}

Experiments were performed in two reactors; a plug flow reactor for measurement of gaseous oxidation products and in a batch system for the determination of metal composition in the oil. Both plug flow and batch systems employ fifty percent of oxygen and nitrogen mixtures for several hours in each experiment. Emission of gaseous products during the reaction was quantified by micro gas chromatography ( $\mu \mathrm{GC})$, and identified by Fourier transform infrared spectroscopy (FTIR) and gas chromatography-mass spectrometry (GC-MS). Oil samples from batch system were digested using microwave and the metal composition was determined by inductively coupled plasma-optical emission spectrometer (ICP-OES).

Boiled linseed oil is the most reactive oil studied, followed by raw linseed oil and refined linseed oil which display similar reactivity, while the least reactive is stand linseed oil. ICP analysis confirmed the presence of cobalt in the boiled linseed oil, which enhances the rate of oxidation reaction. For boiled linseed oil, the cobalt in the oil enhances the decomposition of peroxide resulting in the formation of various radicals which oxidize the oil and the cotton wool, therefore the emission of gaseous products is higher during oxidation on the cotton wool support compared to glass wool and thus boiled linseed oil has the highest tendency to self heat, especially if soaked on the cotton or rags.

A kinetic model of peroxide formation and decomposition has been developed based on the experimental data. The reaction rate constant of the decomposition of peroxide has been found to be higher in the reaction using cobalt compared to that of without cobalt, confirming the role of cobalt in catalysing the peroxide decomposition reaction. Abstraction reactions by the radicals during oxidation lead to subsequent reactions which are generally very exothermic. Accumulation of sufficient heat, can ultimately lead to the temperature reaching the ignition point of the oil and causing the self- heating and even ignition of the oil.

KEYWORDS: self-heating, ignition, boiled linseed oil, cotton, cobalt.

\section{INTRODUCTION}

Linseed oil has been widely used in industrial products such as paint and linoleum floor covering. It is the natural oil type from the seed of the flax plant (Linum usitatissimum) [1] and is classified as a drying oil as it contains a high percentage of esters of polyunsaturated fatty acids [2]. This oil is characterized by high levels of linolenic acid [1]. Typical linseed oil contains triglyceride esters of monocarboxylic fatty acids, including palmitic acid (16:0, 6-7 \%), stearic acid (18:0, 3-6\%), oleic acid (18:1, 14-24\%), linoleic acid $(18: 2,14-19 \%)$ and linolenic acid $(18: 3,48-60 \%)$ [3], where the first number in each ratio indicates the length of the carbon chain and the second corresponds to the number of unsaturated bonds [4]. The drying propensity of fatty acid depends on several factors such as the number of double bonds, the conjugated arrangement and the trans isomerism [5].

There are varieties of linseed oil available in the market, including raw linseed oil, boiled linseed oil, stand linseed oil and refined linseed oil. Raw linseed oil has been extracted and packaged without any additional 
additives, and this oil takes significantly longer to dry than boiled linseed oil. Boiled linseed oil has been treated through the addition of metallic dryers to speed its drying time. Stand linseed oil is produced by heating the oil thus increasing its viscosity through a polymerization process. Refined linseed oil is used as a medium for oil colours to increase gloss and transparency. Metal salts have been used as additives to promote the transformation of paint films from the liquid to the solid state following application on a surface [6].

Our previous paper [7] offered an explanation of the role of peroxide in the oxidation reaction and self heating of linseed oil. The initial step in the process was conjectured to involve non-conjugated double bonds, present in compounds such as linolenic acid or linoleic acid in the linseed oil. The abstraction of double allylic hydrogen produces an alkyl radical which can react with oxygen to form peroxy radicals. This radical then abstracts a hydrogen atom to form peroxide compounds. The notable build-up of peroxide compounds illustrates that the formation of peroxide is dominant during the early stage of oxidation. In the presence of the cobalt catalyst, the observed decrease in the concentration of peroxide indicates that the rate decomposition of peroxide is higher than its rate of formation in the presence of cobalt [7].

Most peroxides are stable at room temperature, although they can be decomposed by heating, exposure to UV light or by the addition of transition metal salts [8]. Metal catalysts enhance the decomposition of hydroperoxide which increases the overall paint drying rate [9]. We have studied several transition metals and found that the most effective catalyst for the peroxide decomposition and polymerisation reaction is cobalt(II) nitrate, followed by manganese nitrate and finally, cerium nitrate is the least effective [7]. The decomposition products of peroxide substances include alkoxy, peroxy and hydroxy radicals, and the last is known to be a very active radical which can abstract hydrogen from the parent oils and hence initiate oxidation chain reactions. The abstraction reactions consuming hydroxy radical are generally very exothermic, typically $75-100 \mathrm{~kJ} \mathrm{~mol}^{-1}$ for alkanes, with low activation energies hence these reactions are relatively fast, even at room temperature and below [10]. This mechanism may be responsible for the self heating of linseed oil. The $\mathrm{OH}$ radical is the primary species responsible for the consumption of organic compounds under atmospheric conditions [10].

Carbon dioxide is the dominant gaseous species produced, with other products, including carbon monoxide, ethane, ethylene, acetaldehyde, propionaldehyde, acrolein and formic acid, formed at lower yields. Oxidation can proceed in a controlled manner via 'slow reactions' or through a rapid increase in rate which leads to explosion or ignition. There are two ways of causing an increased rate; through the exponential increase in the number of radicals or chain branching reactions and the effect of a rapid temperature rise as a result of exothermic reactions [10]. In the present experiments, we aim to study several types of linseed oil in the market and their tendency to cause spontaneous combustion.

\section{EXPERIMENTAL}

\section{Materials}

Ultra high purity (UHP) oxygen and nitrogen gases were obtained from Air Liquide. We employed commercial raw linseed oil, boiled linseed oil, stand linseed oil and refined linseed oil purchased in a hardware store. The oil was manufactured by Sceneys Pty. Ltd. (Australia). All compounds were used without purification.

\section{Experimental Apparatus}

We performed, in two different systems, oxidation or ignition experiments in a plug flow reactor and oxidation experiments in a batch reactor (with residue to be analysed by ICP (inductively coupled plasma) instrument) to determine the metal content in the oil.

\section{Oxidation Experiments in Plug Flow Reactor}

Figure 1 illustrates the oxidation and ignition experiments of linseed oil that were performed in a plug flow reactor. This figure has been modified from our previous paper by implementing a pressure relief valve for safety concern. The reactor, made of copper, and located inside a Thermoline oven, operated at temperatures of either 80 or $100{ }^{\circ} \mathrm{C}$. The dimension of the reactor was $11.8 \mathrm{~cm}$ in length and $0.94 \mathrm{~cm}$ in diameter. We employed a glass reactor in the ignition experiment to visually observe whether the reaction 
is confined to gas/solid reaction or whether ignition has occurred. A tee fitting afforded the insertion of a thermocouple to measure the temperature rise inside the reactor, and a Type-K thermocouple, with a wire thickness of $0.2 \mathrm{~mm}$ with an exposed junction, was used to ensure fast response times. Prior to entering the reactor, the oxygen and nitrogen gases were metered by mass flow controllers and mixed in equimolar proportions. Mixing of feed gases was enhanced by a particulate filter. The feed gases were preheated in copper coil tubing in the reactor oven, which allowed the temperature of the feed gases to equilibrate with the oven temperature. A silica gel trap removed moisture from the gases flowing into the oven. A check valve, mounted on the gas line leading to the oven, ensured no back flow was possible. A pressure relief valve was placed upstream in the reactor to release the overpressure should blockage occur in the system and relieve any pressure build up inside the reactor during ignition. The output of the relief valve was connected to the exhaust system. Two three-way valves in a bypass system inside the oven enabled flushing of the tubing and fittings to remove any contaminants before the gases started to flow through the reactor. The exhaust gas stream was analysed using micro gas chromatograph for quantification of product gases.

Glass wool or cotton wool substrate was impregnated with around $0.2 \mathrm{~g}$ of oil samples then the impregnated substrate was inserted into the reactor to dry under flowing $\mathrm{N}_{2}$ at $40{ }^{\circ} \mathrm{C}$. The oxygen-nitrogen mixture, flowing at a total flow rate of $13 \mathrm{~cm}^{3} \cdot \mathrm{min}^{-1}$ (STP) passed through the sample in each experiment for several hours.

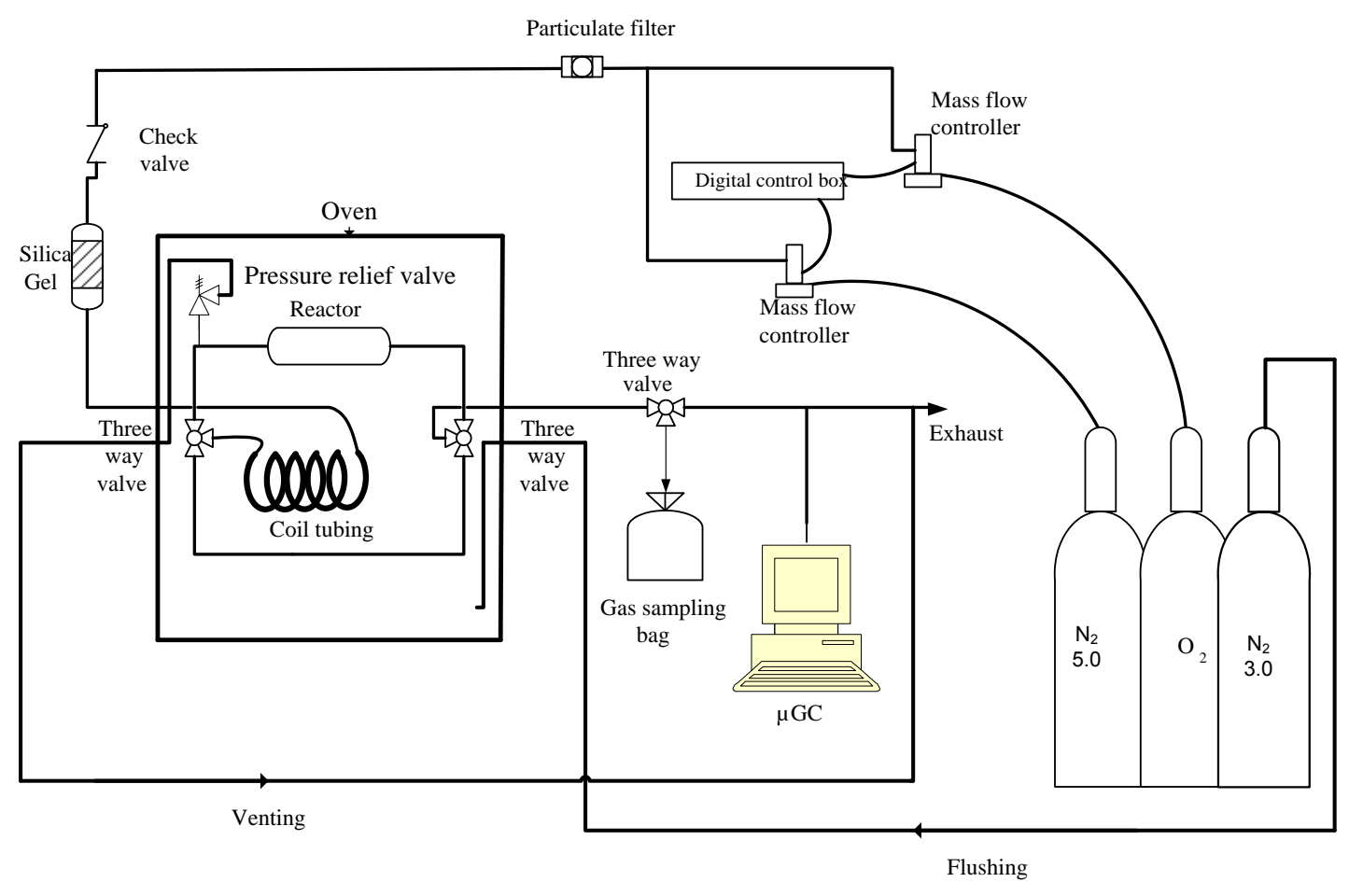

Fig. 1. Schematic diagram of the experimental apparatus with plug flow reactor for the oxidation of linseed oil [11].

\section{Oxidation in Batch Reactor}

Experiments were performed in a glass batch reactor with magnetic stirrer on the bottom to enhance the mixing of oil and metal salts. A heating plate with temperature and speed control was used to control the temperature of the reactor and speed of mixing. There are two tubes connected to the reactor, one to sweep the gases from inside the reactor to the exhaust and the other to flow the mixture of oxygen and nitrogen to the bottom of the reactor. Calibrated mass flow controllers were used to meter the flow rate of oxygen and nitrogen. The experiment was started by placing around $20 \mathrm{~g}$ of linseed oil in the reactor. Around $0.2 \%$ of metal salt was then added to the oil. The reactor was placed on the heating plate, which was set to $100{ }^{\circ} \mathrm{C}$. The schematic of the reactor was presented in our previous paper [7]. 


\section{Microwave Digestion}

Digestion of oil sample was necessary in order for it to be analysed by ICP. Preparation was started by accurately weighing approximately $100 \mathrm{mg}$ of oil sample into a teflon vessel ensuring all sample is transferred to the bottom of the vessel. If any sample stays on the inner wall of the vessel, it will create a hot spot during the microwave program and damage the teflon vessel. $7 \mathrm{~mL}$ of $65 \%$ nitric acid and $1 \mathrm{~mL}$ of $30 \%$ hydrogen peroxide were then added to digest the sample. It was essential to use the same acid mixture in all the vessels to ensure a homogenous temperature in all. Each vessel was spiked with the required amount of internal standard (Yttrium $1000 \mathrm{ppm}$ ). We assembled the teflon insert, ceramic body with disc and PEEK outer casing and placed the cover on the vessels. The thermowell for inserting thermocouple and the protection foil (thin plastic disc) must be in place on the cover for the reference vessel before being introduced into the rotor body. The vessels were installed in the rotor.

Loaded carousel (rotor and the vessel installed) was put into the microwave with thermocouple cable inserted. We operated the microwave through the controller. Exhaust nozzle of the microwave was connected to the exhaust hood. The microwave program for the oil digestion consisted of two steps, first, heating up to $200{ }^{\circ} \mathrm{C}$ for $10 \mathrm{~min}$ and second, keeping the temperature at $200{ }^{\circ} \mathrm{C}$ for $15 \mathrm{~min}$. This instrument is completed with an acid sensor to monitor the acid level inside the microwave room.

\section{Analytical Methods}

\section{Micro Gas Chromatography Analysis}

Quantification of the oxidation product gases was performed online on a Varian CP-4900 micro gas chromatograph $(\mu \mathrm{GC})$ connected to the output of the reactor. The instrument was equipped with thermal conductivity detectors to quantify the product species. Helium was used as a carrier gas, operated at pressure of $550 \mathrm{kPa}$. Gas clean filters were inserted into the helium line to remove traces of moisture and oxygen. Separation of the product gases was performed using Molsieve 5A and PoraPLOT Q columns, operated at $80{ }^{\circ} \mathrm{C}$ and $103.4 \mathrm{kPa}$. We used a sampling time of $30 \mathrm{~s}$, and an injection time for the Molsieve column of $400 \mathrm{~ms}$ and $40 \mathrm{~ms}$ for the PoraPLOT column. Carbon monoxide was analysed on the Molsieve column, while carbon dioxide, ethane, ethylene, water, acetaldehyde and propionaldehyde on the PoraPLOT Q column.

We quantified carbon dioxide and carbon monoxide using standard calibration gases. Ethane, ethylene, acetaldehyde, propionaldehyde were quantified by applying their relative molar response factors (RMR). Quantification methods have been described in our previous paper [7].

\section{Fourier Transform Infrared Analysis}

Gas sampling bags collected and stored the reaction product gases for analysis on a Varian IR-660 Fourier transform infrared spectrometer. This spectrometer was equipped with a $10 \mathrm{~m}$ long path gas cell, $\mathrm{KCl}$ windows, and a DLa Peltier cooled TGS detector. It was operated with a spectral resolution of $0.5 \mathrm{~cm}^{-1}$. Prior to experiments, each gas bag was evacuated under vacuum and then filled with ultra high purity (UHP, $99.999 \%$ ) nitrogen. This was repeated at least four times to ensure the removal of trace quantities of gases from the previous analysis. A similar procedure was adopted for the multipath cell. Before the analysis of each sample, a background spectrum was acquired by filling the bag with ultra high purity nitrogen, with nitrogen transferred to the previously vacuumed gas cell. Subsequently, the gas cell was topped up with additional UHP nitrogen until the pressure reached $101.3 \mathrm{kPa}$, followed by the acquisition of the background spectrum. The acquisition of the spectra involved 52 scans with subsequent subtraction of the background spectra. QASoft and Gram software packages aided the detection of product gases from measured spectra.

The identification of the product species as the result of the linseed oil degradative oxidation was performed using FTIR spectra by comparing measured and reference (library) spectra. In addition to carbon dioxide and monoxide, we observed formic acid, propionaldehyde, acetaldehyde, acrolein, crotonaldehyde, ethane. The reader is referred to reference [7], for details of the analysis. 


\section{Gas Chromatography-Mass Spectrometry Analysis}

We employed a Shimadzu GC-MS QP-5000, operating with a fused silica capillary Supel-Q PLOT column $30 \mathrm{~m} \times 0.32 \mathrm{~mm}$ i.d. $\times 15 \mu \mathrm{m}$ thickness to identify the product gases. Helium was the carrier gas flowing through the column at $1.5 \mathrm{~cm}^{3}$ per minute. The GC detector was assembled to operate in split mode $(5: 1)$ and $0.5 \mathrm{~cm}^{3}$ of sample was injected for each analysis. The operating conditions of the GC were as follows: The oven temperature was set initially at $35^{\circ} \mathrm{C}$, held for $5 \mathrm{~min}$, then the oven temperature was increased to $230{ }^{\circ} \mathrm{C}$ at a rate of $18{ }^{\circ} \mathrm{C} / \mathrm{min}$ and then held at $230^{\circ} \mathrm{C}$ for $10 \mathrm{~min}$. Injector and detector temperatures were held at $220^{\circ} \mathrm{C}$ and $230{ }^{\circ} \mathrm{C}$, respectively. Further operating parameters of the mass spectrometer included a scan interval of $0.5 \mathrm{~s}$, detector voltage of $1.6 \mathrm{kV}$ and MS range of $\mathrm{m} / \mathrm{z} 20-350$.

\section{Inductively Coupled Plasma-Optical Emission Spectrometer Analysis}

Determination of metal composition in the oil sample was performed using ICP-OES. Argon was used as a carrier gas, operated at pressure of $550 \mathrm{kPa}$. The conditions implemented for analysis included power of $1.2 \mathrm{~kW}$, plasma flow of $15 \mathrm{~L} / \mathrm{min}$, nebulizer pressure of $200 \mathrm{kPa}$, instrument stabilisation delay of $10 \mathrm{~s}$, sample uptake delay of $10 \mathrm{~s}$, pump rate of $10 \mathrm{rpm}$ and rinse time of $10 \mathrm{~s}$. Standard solution containing several metal salts with known concentrations was used to produce the calibration curve.

\section{RESULTS AND DISCUSSION}

Figure 2 illustrates the comparison of several kinds of linseed oil found in the market, viz., raw linseed oil, boiled linseed oil, stand linseed oil and refined linseed oil during oxidation at $80^{\circ} \mathrm{C}$ on glass wool support. It is clearly shown that boiled linseed oil is the most reactive oil. The maximum concentration of carbon dioxide emitted during oxidation of boiled linseed oil (around $250 \mathrm{ppm}$ ) is the highest and is achieved in the shortest time of one hour. This is followed in reactivity by raw linseed oil and refined linseed oil which show similar reactivity. The least reactive is stand linseed oil from which the maximum concentration of carbon dioxide production is $110 \mathrm{ppm}$ and is achieved in five hours. Similar profiles were obtained from $\mu \mathrm{GC}$ analysis for carbon monoxide, ethane, ethylene, propionaldehyde and acetaldehyde. Thompson reported about the higher tendency of boiled linseed oil to oxidize than raw linseed oil [12].

This result illustrate that the presence of metallic drier in the boiled linseed oil speeds up the oxidation reaction. Our previous study illustrated the performance of several transition metal salts which we found to catalyse the oxidation reactions of linseed oil. Cobalt(II) is the most effective catalyst among other transition metal salts, which we studied, followed by manganese(II) and iron(II) [4]. Ignition experiments have been undertaken in order to investigate the spontaneous combustion of cotton rags doused with linseed oil. In our previous paper, we hypothesised that metallic driers and pigments used in paints were implicated in these phenomena. Oily waste used for cleaning of rusty machinery has higher possibility to ignite due to the presence of iron [12]. Cobalt(II) nitrate hexahydrate was employed to check the tendency of linseed oil to self ignite. Experiments involving cotton wool impregnated with cobalt(II) nitrate illustrated that ignition occurred at an initial temperature of $82{ }^{\circ} \mathrm{C}$ [4]. This highlights the important role that cobalt plays in the spontaneous combustion. Metal catalysts present in oil driers and pigments, such as cobalt(II), induce faster initiation of exothermic reactions. Heat generated by these oxidation reactions can then accumulate, accelerating the reactions and leading to self-ignition. 


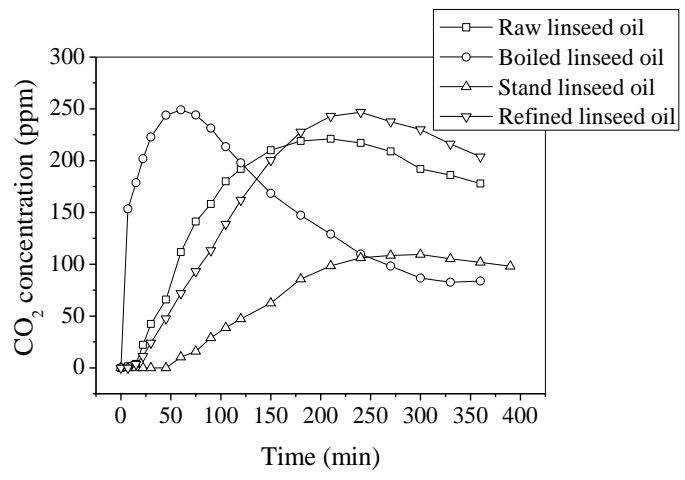

(a)

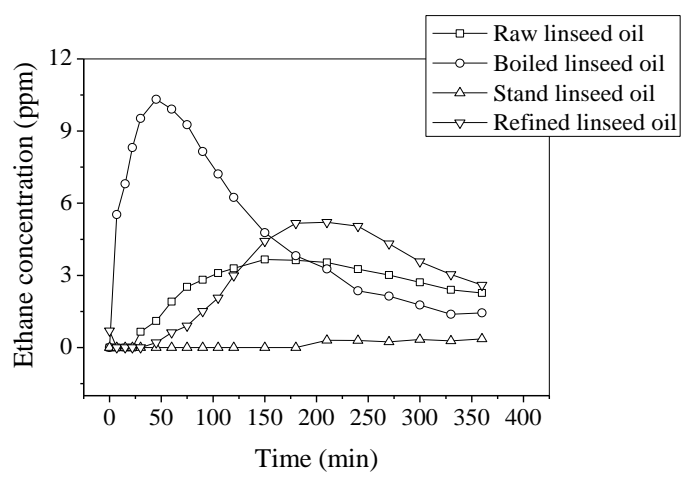

(c)

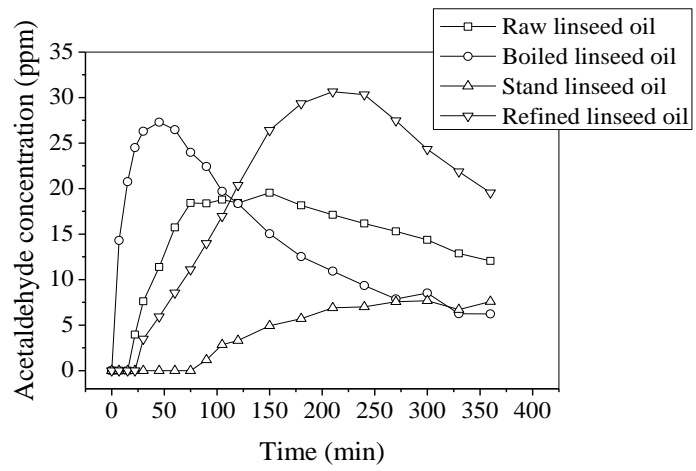

(e)

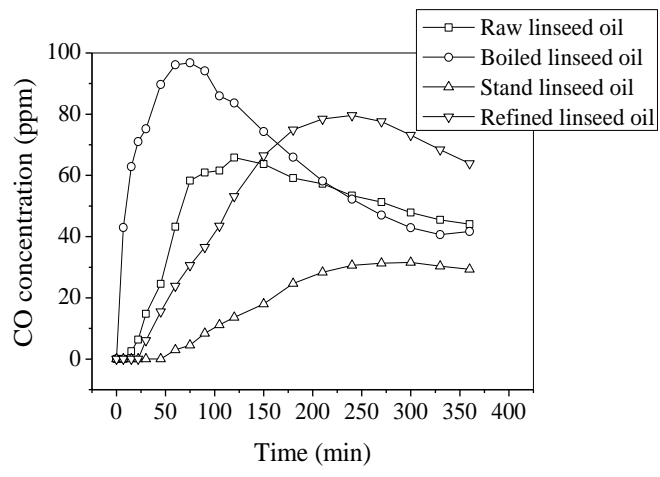

(b)

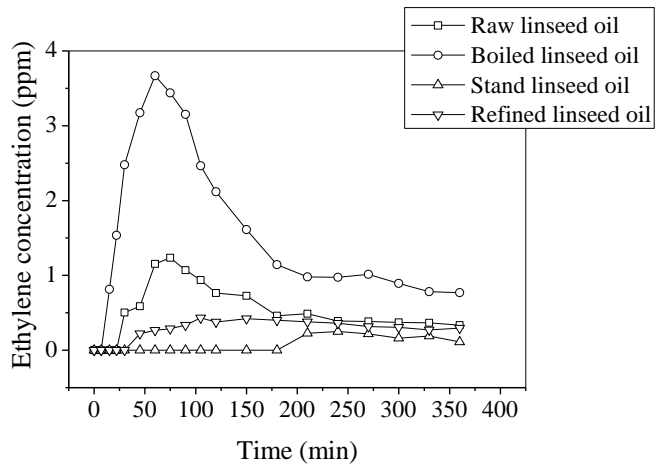

(d)

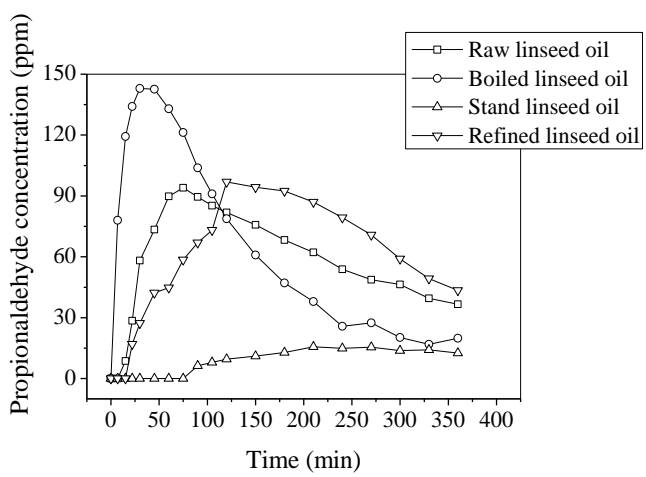

(f)

Fig. 2. The comparison of effect of several kinds of linseed oil, raw linseed oil, boiled linseed oil, stand linseed oil and refined linseed oil on the product formation during oxidation at $80{ }^{\circ} \mathrm{C}$ on glass wool support:

(a) carbon dioxide; (b) carbon monoxide; (c) ethane; (d) ethylene; (e) acetaldehyde; (f) propionaldehyde.

ICP analysis was used to determine the type of metal and the composition of it in the boiled linseed oil. We also performed analysis for other types of linseed oil: raw linseed oil, stand linseed oil and refined linseed oil. We detected a peak at the wavelength of $230.786 \mathrm{~nm}$ illustrating the presence of cobalt in the boiled linseed oil. On the other hand, we could not find any cobalt in raw linseed oil, stand linseed oil or refined linseed oil. This implies the tendency of boiled linseed oil to self heat should be higher than other kinds of linseed oil. Several cases of fire, involving linseed oil, have been reported, in particular those induced by improperly disposed rags soaked with this oil. We suggest that boiled linseed oil has a higher probability as the source of those cases of fire. The average intensity for cobalt at $230.786 \mathrm{~nm}$ is $176.8 \mathrm{c} / \mathrm{s}$. From the calibration curve, we obtain the concentration of cobalt as $0.83 \mathrm{ppm}$ and the composition of cobalt in the 
boiled linseed oil is $0.017 \%$. The cobalt balance has been examined through the digestion using microwave and ICP analysis. The oil samples were taken from the batch reactor during the oxidation reaction of linseed oil and the results show that the cobalt concentration remains the same during several hours of reaction.

The type of wool substrate affects the oxidation of linseed oil as indicated in Fig. 3a. In the presence of raw linseed oil, the maximum concentration of carbon dioxide emitted in the experiment involving glass wool substrate is $850 \mathrm{ppm}$ higher than using cotton wool substrate, at around $740 \mathrm{ppm}$. The reaction time to achieve the maximum concentration of product using glass wool is one hour, much faster compared with using cotton wool for which it is three hours. There is an induction period of about 50 min clearly seen for experiment on the cotton wool substrate before a fast increase of carbon dioxide. This agrees with the experimental measurements reported by Lazzari and Chiantore who observed a fast increase in the abundance of hydroxyl groups after an induction time of about $4 \mathrm{~h}$ [13]. In this case, cotton wool exhibits an inhibiting effect on the oxidation, possibly as a result of antioxidant present in the cotton wool. These antioxidants will need to be consumed prior to the appearance of the oxidation reaction involving the active components of the linseed oil. However, in the presence of boiled linseed oil, the trend is opposite. The oxidation of linseed oil on the cotton wool substrate is faster and produces higher emission of product compared to that on the glass wool. It seems that cobalt in the boiled linseed oil has an important role in the oxidation of cotton wool in addition to the oxidation of linseed oil hence carbon dioxide released is higher in the presence of cotton wool. Cobalt catalyses the oxidation process so that the induction period is no longer present.

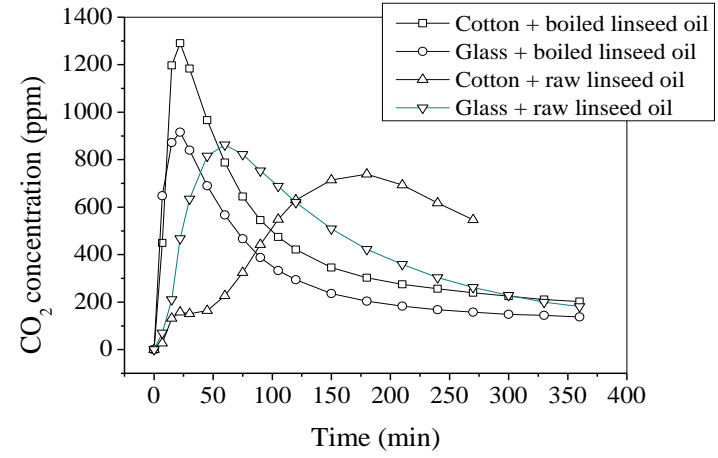

(a)

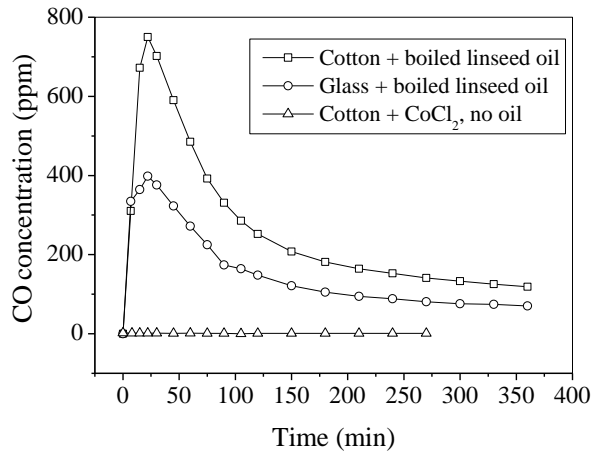

(b)

Fig. 3. (a) The effect of substrate and linseed oil type on the carbon dioxide emission during oxidation of linseed oil at $100{ }^{\circ} \mathrm{C}$; (b) The comparison between the presence of cobalt salt and cobalt in the boiled linseed oil on the carbon monoxide production during oxidation on the wool substrate.

In order to investigate the role of cobalt in the oxidation of cotton, we carried out experiments involving cotton wool impregnated with cobalt chloride without any linseed oil and the result in Fig. 3b shows that there is no oxidation without any linseed oil, even though cobalt salt was present. The weak allylic H-bonds in the molecules in linseed oil represent a facile target for initial radical attack. Initiation reaction would be expected to proceed with the abstraction of an allylic hydrogen atom from the molecules to form a free, but stable, allylic radical [4]. The allylic-type radical can undergo the addition of molecular $\mathrm{O}_{2}$ to form a peroxy radical. Subsequently, this radical abstracts an allylic hydrogen from another parent molecule to form a hydroperoxide which then decomposes into alkoxy and hydroxyl radicals. This chain of events supports the propagation of the autoxidation reaction [13]. Metal catalysts can reduce the activation energy required for the decomposition of hydroperoxide from $45-85$ to $20-25 \mathrm{~kJ} \mathrm{~mol}^{-1}$ [14]. Cobalt as the most widely used drier in paint [15] has been reported to catalyse the decomposition of hydroperoxides [16]. Therefore, this catalysis process enhances the rate of formation of radicals, leading to the higher oxidation rate [7]. Without any oil, there is no radical formed in the system thus the oxidation of cotton cannot occur. On the other hand, in the presence of boiled linseed oil, the cobalt in the oil enhances the formation of radicals and is able to oxidize the oil and cotton, therefore the carbon dioxide and carbon monoxide emitted are higher during oxidation on cotton wool support. The ratio of oil to cotton affects the heating rate, which the most rapid heating occurs when the cotton fibres are coated with thinnest film of oil covering all the 
surfaces [12]. Rags covered with linseed oil has greater surface to volume ratio for contact between air and oil than bulk of oil [5] hence the tendency to self heat is higher.

Peroxide is an important substance in the oxidation reaction of linseed oil. Peroxide value determination has been used as a way to estimate the extent of oxidation and curing [14]. We did some modelling calculations to determine the appropriate model to fit the experimental peroxide profiles during oxidation. The reaction mechanism for peroxide formation and decomposition is proposed below and has been modelled using DynaFit software [17]. The reaction essentially comprises peroxide formation which is predominant during the early stage of oxidation and after reaching a maximum peroxide value, it decreases gradually due to decomposition of the formed hydroperoxides. It implies that during the later stage, the decomposition reaction is faster than the formation reaction resulting in the decreasing amount of peroxide. RH in the reaction represents the oil sample and consists of mostly unsaturated hydrocarbon as described in the introduction. The initial concentration of RH is given by the total amount of allylic hydrogen in the oil as the active sites for the initiation reaction to occur. This compound then reacts with oxygen to form organic peroxide which then decomposes into alkoxy and hydroxyl radicals. Alkoxy radicals can cross link with each other to form polymerisation product and also can undergo scission reaction to form products such as aldehydes, acids and lower hydrocarbons.

$$
\begin{aligned}
& \mathrm{RH}+\mathrm{O}_{2} \stackrel{\mathrm{k}_{1}}{\longrightarrow} \mathrm{ROOH} \\
& \mathrm{ROOH} \stackrel{\mathrm{k}_{2}}{\longrightarrow} \mathrm{RO}+\mathrm{OH} \\
& \mathrm{RH}+\mathrm{OH} \stackrel{\mathrm{k}_{3}}{\longrightarrow} \mathrm{H}_{2} \mathrm{O}+\mathrm{R} \\
& \mathrm{O}_{2}+\mathrm{R} \stackrel{\mathrm{k}_{4}}{\longrightarrow} \mathrm{ROO} \\
& \mathrm{RH}+\mathrm{ROO} \stackrel{\mathrm{k}_{5}}{\longrightarrow} \mathrm{ROOH}+\mathrm{R} \\
& \mathrm{ROOH} \stackrel{\mathrm{k}_{6}}{\longrightarrow} \mathrm{ROO}+\mathrm{H} \\
& \mathrm{RO}+\mathrm{RO} \stackrel{\mathrm{k}_{7}}{\longrightarrow} \mathrm{ROOR}
\end{aligned}
$$

The differential equations developed from the reaction mechanisms can be described as in the following reactions. After solving the several differential equations and fitting to the peroxide profiles, we obtain the reaction rate constants as described in Table 1 . We fitted the model for the two different conditions of oxidation, in the presence of cobalt and without any cobalt. The reaction rate constant for the decomposition of peroxide $\left(\mathrm{k}_{2}\right)$ is much higher in the presence of cobalt. It supports the statement that cobalt catalyses the decomposition of peroxide, and why the rate of peroxide decomposition is higher in boiled linseed oil than in the other types of oils.

$$
\frac{d[\mathrm{RH}]}{d t}=-k_{\mathbf{1}}[\mathrm{RH}]\left[\mathrm{O}_{2}\right]-k_{\mathbf{3}}[\mathrm{RH}][\mathrm{OH}]-k_{\mathbf{5}}[\mathrm{RH}][\mathrm{ROO}]
$$




$$
\begin{aligned}
& \frac{d\left[\mathrm{O}_{2}\right]}{d t}=-k_{1}[\mathrm{RH}]\left[\mathrm{O}_{2}\right]-k_{4}\left[\mathrm{O}_{2}\right][\mathrm{R}] \\
& \frac{d[\mathrm{ROOH}]}{d t}=k_{\mathbf{1}}[\mathrm{RH}]\left[\mathrm{O}_{2}\right]-k_{\mathbf{2}}[\mathrm{ROOH}]+k_{\mathbf{5}}[\mathrm{RH}][\mathrm{ROO}]-k_{\mathbf{6}}[\mathrm{ROOH}] \\
& \frac{d[\mathrm{RO}]}{d t}=k_{2}[\mathrm{ROOH}]-k_{7}[\mathrm{RO}]^{2} \\
& \frac{d[\mathrm{OH}]}{d t}=k_{\mathbf{2}}[\mathrm{ROOH}]-k_{\mathbf{3}}[\mathrm{RH}][\mathrm{OH}] \\
& \frac{d\left[\mathrm{H}_{2} \mathrm{O}\right]}{d t}=k_{3}[\mathrm{RH}][\mathrm{OH}] \\
& \frac{d[\mathrm{R}]}{d t}=k_{\mathbf{3}}[\mathrm{RH}][\mathrm{OH}]-k_{\mathbf{4}}\left[\mathrm{O}_{2}\right][\mathrm{R}]+k_{\mathbf{5}}[\mathrm{RH}][\mathrm{ROO}] \\
& \frac{d[\mathrm{ROO}]}{d t}=k_{4}\left[\mathrm{O}_{2}\right][\mathrm{R}]-\mathrm{k}_{5}[\mathrm{RH}][\mathrm{ROO}]+\mathrm{k}_{6}[\mathrm{ROOH}] \\
& \frac{d[\mathrm{H}]}{d t}=k_{6}[\mathrm{ROOH}] \\
& \frac{d[\mathrm{ROOR}]}{d t}=k_{7}[\mathrm{RO}]^{2}
\end{aligned}
$$

Table 1. Reaction rate constants in peroxide formation and decomposition reaction.

\begin{tabular}{|l|r|r|}
\hline Reaction rate constant $(\mathbf{k})$ & Without cobalt & \multicolumn{1}{c|}{ With cobalt } \\
\hline$k_{1}(\mathrm{~kg} / \mathrm{mmol} \cdot \mathrm{min})$ & $1.627 \times 10^{-7}$ & $2.076 \times 10^{-7}$ \\
\hline$k_{2}\left(\mathrm{~min}^{-1}\right)$ & $2.733 \times 10^{-5}$ & $1.835 \times 10^{-2}$ \\
\hline$k_{3}(\mathrm{~kg} / \mathrm{mmol} \cdot \mathrm{min})$ & $1.000 \times 10^{-11}$ & $1.000 \times 10^{-11}$ \\
\hline$k_{4}(\mathrm{~kg} / \mathrm{mmol} \cdot \mathrm{min})$ & $6.032 \times 10^{-6}$ & $2.222 \times 10^{-3}$ \\
\hline$k_{5}(\mathrm{~kg} / \mathrm{mmol} \cdot \mathrm{min})$ & $6.272 \times 10^{-6}$ & $4.330 \times 10^{-6}$ \\
\hline$k_{6}\left(\mathrm{~min}^{-1}\right)$ & $5.457 \times 10^{-2}$ & $3.976 \times 10^{-1}$ \\
\hline$k_{7}(\mathrm{~kg} / \mathrm{mmol} \cdot \mathrm{min})$ & $1.000 \times 10^{1}$ & $9.171 \times 10^{-6}$ \\
\hline
\end{tabular}

Figure 4 illustrates the trend of peroxide value during oxidation of raw linseed oil in the presence of cobalt(II) nitrate of $0.1 \%$ (Fig. 4a) and of no cobalt (Fig. 4b). It clearly shows that the maximum of peroxide value is much lower (around $140 \mathrm{mmol} / \mathrm{kg}$ ) in the reaction using cobalt compared to that of the oxidation without cobalt (around $550 \mathrm{mmol} / \mathrm{kg}$ ). During the early stage, the peroxide profile is steeper in the presence of cobalt, suggesting that cobalt also affects the rate of peroxide formation, higher than the one 
without cobalt. The oxidation time is shortened with a maximum concentration of peroxide observed after one hour in the oil contains cobalt compared to five hours in the raw linseed oil without cobalt.

The proposed kinetic model for peroxide formation and decomposition has been plotted in Fig. 4 and it demonstrates that the model give a quite satisfactory prediction of the experimental data. These data support the role of cobalt in the decomposition of peroxide and that the product of the decomposition can react further to give the emission of oxidation products. The model can be developed further to predict the profile of peroxide and oxidation products of different types of linseed oil in the market based on the composition of metal (cobalt) in the oil and the number of allylic hydrogens as the active sites. Therefore this model will be able to estimate the tendency of that oil to self heat.

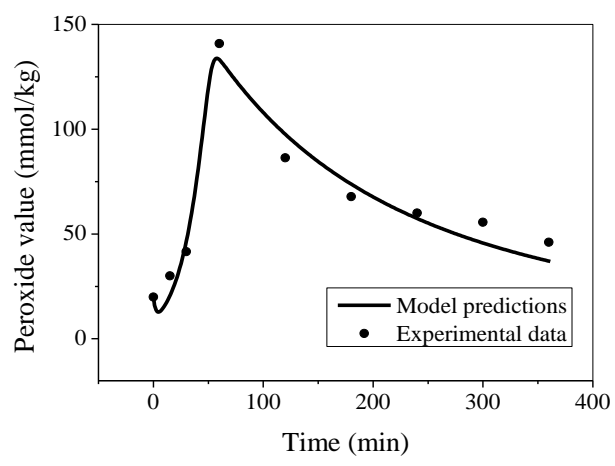

(a)

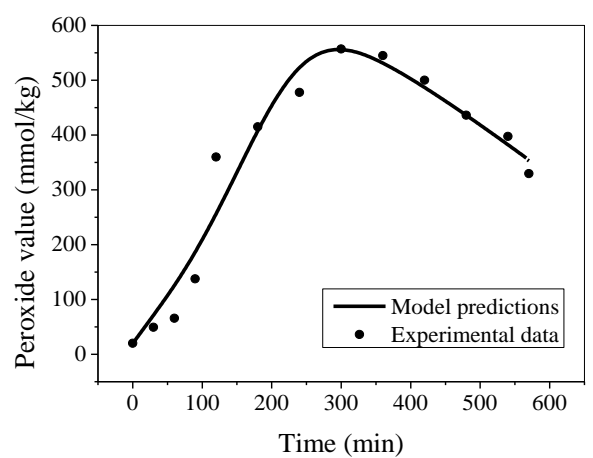

(b)

Fig. 4. Profiles of peroxide during oxidation reaction of raw linseed oil in the batch reactor at $100{ }^{\circ} \mathrm{C}$ and the model predictions fitted to the experimental data: (a) In the presence of cobalt(II) nitrate $0.1 \%$; (b) without any cobalt.

In the reaction in which cobalt catalyses the decomposition of peroxide to form alkoxyl radical and hydroxyl ion, we calculated thermodynamically the enthalpy of the decomposition reaction. This process represents the key reaction step, which is shown in the reaction mechanism previously as reaction (2). In the absence of specific data, the simplest peroxide has been used as representative. Based on the data in Table 2, we obtained the enthalpy of reaction of $68 \mathrm{~kJ} / \mathrm{mol}$ by subtracting the total enthalpy of products with the total enthalpy of reactants. This value implies that the reaction is feasible at low temperature. The reaction can be described as the following:

$\mathrm{CH}_{3} \mathrm{OOH}+\mathrm{Co}^{2+} \rightarrow \mathrm{CH}_{3} \mathrm{O}^{\cdot}+\mathrm{OH}^{-}+\mathrm{Co}^{3+}$

Table 2. The enthalpy data of several compounds related with the decomposition of peroxide.

\begin{tabular}{|l|l|}
\hline Compound & Enthalpy (kJ/mol) \\
\hline $\mathrm{CH}_{3} \mathrm{OOH}$ & $-131[18]$ \\
\hline $\mathrm{Co}^{2+}$ & $-58[19]$ \\
\hline $\mathrm{Co}^{3+}$ & $92[19]$ \\
\hline $\mathrm{CH}_{3} \mathrm{O}^{\cdot}$ & $17[20]$ \\
\hline $\mathrm{OH}^{-}$ & $-230[19]$ \\
\hline
\end{tabular}

\section{CONCLUSIONS}

Among the varieties of linseed oil studied, boiled linseed oil is the most reactive, followed by raw linseed oil and refined linseed oil which show similar reactivities, while the least reactive is stand linseed oil. ICP analyses confirm the presence of cobalt in boiled linseed oil, which is suggested to enhance the rate of oxidation. Conversely, the absence of cobalt or indeed any metal catalyst in raw linseed oil, stand linseed oil and refined linseed oil makes these oils comparatively much less reactive. This implies the tendency of 
boiled linseed oil to self heat is high compared with other kinds of linseed oil. The composition of cobalt in the boiled linseed oil (as studied) is $0.017 \%$. Elemental cobalt is not consumed during the reaction

The type of wool substrate affects the rate of oxidation of linseed oil. In the presence of raw linseed oil, oxidation on glass wool is faster than on cotton wool. There is an induction period for cotton wool substrate prior to the observed rapid increase of gaseous products, suggesting that cotton wool exhibits an inhibiting effect on the oxidation. However the opposite behaviour was observed with boiled linseed oil, where the cotton wool was observed to have a higher oxidation rate, resulting in the formation of a higher concentration of decomposition products. This suggests that the cobalt in the boiled linseed oil enhances the formation of radicals and is able to oxidize both the oil and the cotton wool, therefore the evolution of gaseous products is higher during oxidation on the cotton wool compared to glass wool. Thus, boiled linseed oil has the highest tendency to self heat, especially if adsorbed on cotton rags.

Peroxide formation and decomposition during the oxidation reaction of linseed oil both in the presence and absence of cobalt salt has been modelled. The reaction rate constant for the decomposition of peroxide is higher in oxidation using cobalt compared to the condition without cobalt, confirming the role of cobalt in catalysing the peroxide decomposition reaction. Upon abstraction by radicals, subsequent oxidation reactions are generally very exothermic. Accumulation of sufficient heat can ultimately lead to the temperature reaching the ignition point of the oil and causing the self-heating and ignition of the oil.

\section{REFERENCES}

[1] Gunstone, F., Fatty acid and Lipid Chemistry, Blackie Academic and Professional, London, 1996, p. 68 .

[2] Kundu, P.P., and Larock, R.C., (2009) Effect of drying catalysts on the properties of thermal copolymers from conjugated linseed oil-styrene-divinylbenzene, Progress in Organic Coatings 65: 10-18, http://dx.doi.org/10.1016/j.porgcoat.2008.08.019.

[3] Lazzari, M., and Chiantore, O., (1999) Drying and oxidative degradation of linseed oil, Polymer Degradation and Stability 65: 303-313, http://dx.doi.org/10.1016/S0141-3910(99)00020-8.

[4] Juita, Dlugogorski, B.Z., Kennedy, E.M., and Mackie, J.C., (2011) Oxidation Reactions and Spontaneous Ignition of Linseed Oil, Proceedings of the Combustion Institute 33: 2625-2632, http://dx.doi.org/10.1016/j.proci.2010.06.096.

[5] Babrauskas, V., Ignition Handbook, Fire Science Publishers, Issaquah, 2003, p. 827, 888.

[6] Miccichè, F., Oostveen, E., Haveren, J.v., and Linde, R.v.d., (2004) The combination of reducing agents/iron as environmentally friendlier alternatives for Co-based driers in the drying of alkyd paints, Progress in Organic Coatings 53: 99-105, http://dx.doi.org/10.1016/j.porgcoat.2004.12.008.

[7] Juita, Dlugogorski, B.Z., Kennedy, E.M., and Mackie, J.C., "The Effect of Transition Metal Salts to the Peroxide Value related to Spontaneous Ignition of Linseed Oil," Proceedings of the 8th Asia-Oceania Symposium on Fire Science and Technology, AOSFST 2010, in Press.

[8] Halliwell, B., and Gutteridge, J.M.C., Free Radicals in Biology and Medicine, Oxford University Press, New York, 2008, p. 51.

[9] Oyman, Z.O., Ming, W., van der Linde, R., van Gorkum, R., and Bouwman, E., (2005) Effect of [Mn(acac)3] and its combination with 2,2'-bipyridine on the autoxidation and oligomerisation of ethyl linoleate, Polymer 46: 1731-1738, http://dx.doi.org/10.1016/j.polymer.2004.12.045.

[10] Pilling, M.J., Low-Temperature Combustion and Autoignition, Elsevier, Amsterdam, 1997, p. X, 38.

[11] Juita, Dlugogorski, B.Z., Kennedy, E.M., and Mackie, J.C., "Effect of Cobalt and Cerium on SelfHeating of Linseed Oil," Proceedings of the $6^{\text {th }}$ International Seminar on Fire and Explosion Hazards, The University of Leeds, Leeds, 2010, in Press.

[12] Thompson, N.J., (1928) The Spontaneous Heating of Oils, Oil and Fat Industries 5: 317-326. http://dx.doi.org/10.1007/BF02562159 
[13] Juita, Dlugogorski, B.Z., Kennedy, E.M., and Mackie, J.C., "Low Temperature Oxidation Reaction of Linseed Oil and its Active Components," Proceedings of the Australian Combustion Symposium, The University of Queensland, Brisbane, 2009, pp. 107-110.

[14] Mallégol, J., Lemaire, J., and Gardette, J.L., (2000) Drier influence on the curing of linseed oil, Progress in Organic Coatings 39: 107-113, http://dx.doi.org/10.1016/S0300-9440(00)00126-0.

[15] Stava, V., Erben, M., Vesely, D., and Kalenda, P., (2007) Properties of metallocene complexes during the oxidative crosslinking of air drying coatings, Journal of Physics and Chemistry of Solids 68: 799-802, http://dx.doi.org/10.1016/j.jpcs.2006.11.019.

[16] Tanase, S., Bouwman, E., and Reedijk, J., (2004) Role of additives in cobalt-mediated oxidative crosslinking of alkyd resins, Applied Catalysis A: General 259: 101-107, http://dx.doi.org/10.1016/j.apcata.2003.09.014.

[17] Kuzmic, P., (1996) Program DYNAFIT for the Analysis of Enzyme Kinetic Data: Application to HIV Proteinase, Analytical Biochemistry 237: 260-273. http://dx.doi.org/10.1006/abio.1996.0238

[18] Khursan, S.L., and Martem'yanov, V.S., (1991) Thermochemistry of the recombination of peroxyl radicals, Russ. J. Phys. Chem 65: 321-325.

[19] Dean, J.A., "Thermodynamic Properties," Lange's Handbook of Chemistry (15 ${ }^{\text {th }}$ ed.), McGrawHill, New York, 1999, pp. 6.90 - 6.104.

[20] Tsang, W., (1996) Heats of Formation of Organic Free Radicals by Kinetic Methods, Structure Energetics and Reactivity in Chemistry Series 4: 22-58. 